elements based on either unique values or a user-controlled value range.

- Automated scale conversion from native co-ordinate system to various traditional scales.

- JAMBuddy export replaced with new pdfPLUS export.

- Correction of several legacy problems with previous versions.

For further information please contact Avenza at (905) 639-3330, info@avenza.com or visit the company's website at http: / / www.avenza.com

\section{Surfer ${ }^{(0)}$ Version 7 Golden Software, Inc.}

Golden Software, Inc. announces the release of Surfer(r) version 7, a contouring and $3 \mathrm{D}$ mapping software package with variogram modeling capabilities. Surfer is a 32-bit program and operates under Windows 95/98, NT 4.0, or higher. It accurately transforms XYZ data into contour, wireframe, vector, image, shaded relief, base, and post maps.

Vector maps are a new map type in Surfer. They instantly show the orientation and inclination of a slope with scaled vectors. Referring to the seven map types available in Surfer, combined with the ability to overlay different map types, Patrick Madison, the President of Golden Software, says that Surfer "has proven to be very versatile in the customization of data presentation."

New, sophisticated gridding filters in Surfer allow the user to accurately grid $X Y Z$ data and to easily exclude unwanted or duplicate data when creating grid files. Variogram modeling has been added to help spatially assess the data and to choose the most accurate gridding method for the specific data. A report of gridding parameters and statistics is automati-

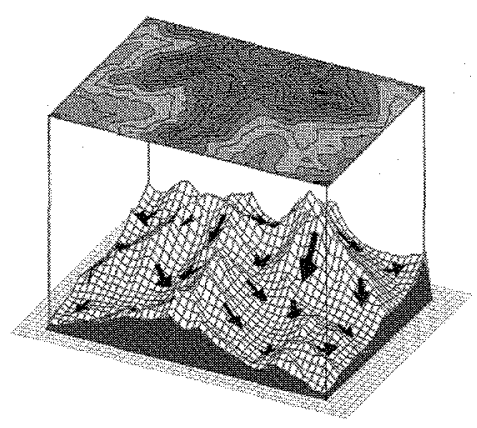

Create and overlay any number of maps in Surfer. In this example, a vector map is overlaid on a $3 D$ wireframe map with a contour map.

cally generated when data are gridded.

Surfer 7 supports more file formats. The list of export options in Surfer now includes SHP, PNG, and 3D DXF file formats. Use USGS SDTS DEM and DLG files in their native formats in Surfer. SDTS DEM files are treated as any other grid file and any grid operation can be performed on the SDTS DEM file.

The new macro system makes the automation of repetitive tasks easier and more versatile in Surfer. Use Visual Basic, $\mathrm{C}++$, Perl, or any ActiveX Automation compatible language to write scripts. Other improvements to the user interface include an object manager, tabbed dialog boxes, and floating toolbars.

A free, full working demo is available on the web page. Contact Golden Software for more information on Surfer version 7.

GoldenSoftware, Inc 809 14th Street Golden, CO 80401 800-972-1021 or 303-279-1021 http:/ / www.goldensoftware.com Email:info@goldensoftware.com

\section{NACIS news}

\section{8-99 NACIS OFFICERS AND BOARD OF DIRECTORS}

\section{NACISOFFICERS:}

President: Cynthia Brewer Pennsylvania State University cbrewer@essc.psu.edu

Vice President:Thomas Patterson National Park Service

t_patterson@nps.gov

Secretary: James O. Minton University of Tennessee jim-minton@utk.edu

Treasurer: Sona Andrews Univ. of Wisconsin-Milwaukee sona@uzm.edu

Past President: Patricia Gilmartin University of South Carolina gilmartin-pat@sc.edu

\section{NACIS EXECUTIVE OFFICERS:}

Christopher Baruth

AGSCollection

cmb@csd.uwm.edu

Sona Andrews

Univ. of Wisconsin-Milwaukee

sona@csd.uwm.edu

Susan Peschel

AGSCollection.

sqp@gml.lib.uwm.edu

\section{NACIS BOARD OF DIRECTORS}

Gregory H. Chu (10/99)

University of Wisconsin-LaCrosse chu@mail.uwlax.edu

Jeremy Crampton (10/99) George Mason University jcrampto@gmu.edu 
Charlie Frye (10/00)

Environmental Systems Research Institute, Inc.

cfrye@esri.com

Mark Harrower (Student Board Member) (10/99)

Pennsylvania State University mah282@psu.edu
Gordon Kennedy (10/00)

Washington State Department of

Transportation

kennedg@wsdot.wa.gov

Dennis McClendon (10/00)

Chicago Cartographics

dmc@ais.net
James E. Meacham (10/99)

University of Oregon

jmeacham@oregon.uoregon.edu

Elisabeth Nelson $(10 / 99)$

Univ. of North Carolina -

Greensboro

Ren Vasiliev (10/00)

vasiliev@geneseo.edu

\begin{tabular}{c} 
PREI MMNARY PROGRAM NACIS XIX \\
The Nineteenth Annual Meeting of the \\
North American Cartographic Information Society \\
wownonacis.org \\
October $20-23,1999$ \\
\hline
\end{tabular}

\section{WEDNESDAY, OCTOBER 20}

\author{
REGISTRATION \\ 2:00-7:30 PM
}

NACIS BOARD MEETING 3:00-5:30 PM

OPENING SESSION (SPEAKER TO BE ANNOUNCED) 7:30-9:00 PM

POSTER SESSION/ EXHIBITS/RECEPTION 9:00-11:00 pm

THURSDAY, OCTOBER 21

Session A HISTORICAL CARTOGRAPHY I 8:00-10:00 am

"A Countrie so Faire". The Mapping of Colonial Virginia Richard Stephenson, Winchester, Virginia

From Battle Plans to Tourist Maps: The Role of the Federal Government in Preserving the Cartographic Heritage of the Williamsburg Yorktown Area

Ronald Grim, Library of Congress
The Promotional Cartography of Captain John Smith John H. Long, The Newberry Library, Chicago

\section{Session B CARTOGRAPHIC METHOD AND THEORY} 8:00-10:00 am

The Basic-level of Cartographic Maps

David K. Patton and Anthony B. Spehar, Slippery Rock Univ.

Visual Perception of Oriented Point Symbols for Mapping

Maureen Ann Kelley, San Jose State University

Color Schemes for Visualizing Climatological and Other Continuous Data

Aileen R. Buckley, Patrick J. Bartlein, and Adam Light, University of Oregon

Feeling it Out: The Use of Haptic Visualization for Exploratory Geographical Analysis

Amy L. Griffin, Dept. of Geography, Pennsylvania State Univ.

\section{Session C HISTORICAL CARTOGRAPHY II} 10:30 am-Noon

Out of bounds, Mapping Over the Edge-A Look at the English View of the Middle Atlantic Colonies Alice C. Hudson, Map Division, NYPL 